\title{
Effect of waterlogged condition on wood properties of Acacia nilotica (L.) debile tree
}

\author{
J. Alam ${ }^{1}$, A. K. Das ${ }^{1,2 *}$, M. M. Rahman ${ }^{1}$ and M. A. Islam ${ }^{1}$ \\ ${ }^{1}$ Forestry and Wood Technology Discipline, Khulna University, Khulna-9208, Bangladesh. \\ ${ }^{2}$ Pulp and Paper Technology, Asian Institute of Technology, Klong Luang, Pathumthani-12120, Thailand.
}

\begin{abstract}
This study is aimed to assess the mechanical and physical properties of waterlogging Acacia nilotica (babla). The important physical and mechanical properties were determined. The oven dry density of the wood of waterlogged tree and non-waterlogged tree was 780 and $850 \mathrm{~kg} / \mathrm{m}^{3}$. The MOR of the wood of waterlogged tree was $117 \mathrm{~N} / \mathrm{mm}^{2}$ while non-waterlogged tree showed the value of MOR $127 \mathrm{~N} / \mathrm{mm}^{2}$. The MOE of the wood of waterlogged tree and non-waterlogged tree was 1880 and $1950 \mathrm{~N} / \mathrm{mm}^{2}$ respectively. The study of properties on $A$. nilotica wood grown in different conditions will help to choose the right type of its wood for suitable purposes.
\end{abstract}

Keywords: Acacia nilotica; Waterlog; Non-waterlog; Physical properties; Mechanical properties

\section{Introduction}

Wood is the result of a biological process. It grows under a wide range of genetic and environmental influences and has a similarly wide range of properties and characteristics (Punches, 2004). Difference between site fertility and geographic location (temperature, sunlight) are the major sources of the variation between different stands (Barntt and Jeronimidis, 2003). Environmental factors affect the structure of the wood of a tree in a number of ways (Desch and Dinwoodie, 1996). Barntt and Jeronimidis (2003) stated that the environment includes a large diversity of factors, that act both below the ground,i.e., moisture, nutrients in the soil and above the ground, i.e., light, temperature.

Acacia nilotica is a useful multipurpose tree and has been traditionally used and planted in Africa and Asia as a source of tannin; brown, grey and black dyes; gum; timber; fodder and fuel. The wood of $A$. nilotica is strong, hard and tough and it takes up a good polish. It is used for such products as bodies and wheels of bullock cart, agricultural instruments, tool handles, and well curbs (Van Wyk et al., 2000). A. nilotica grows well in dry and water logging regions due to its adaptation to different climatic conditions. It meets many of the needs of the local people. Therefore, acacia species are widely distributed through the drier tropical and subtropical regions. It is one of the most successful survivor in arid and semiarid regions, and possess most of the features required to withstand extreme climatic conditions. Acacia trees as xerophytic plants have the ability to resist drought and cope with arid environments through conserving water (Hamad et al., 2006).
The properties of the wood depend upon the environment of area in which it is grown (Punches, 2004). A. nilotica is grown in waterlogged and non-waterlogged areas. The properties indicate the particular uses of the wood. This study was undertaken to determine the physical and mechanical properties of A. nilotica of waterlogged and non-waterlogged area.

\section{Materials and methods}

Acacia nilotica is planted all over Bangladesh. Four trees of 15 years old were collected from Dhalbari in Tala upazila $\left(22^{0} 76^{\prime} \mathrm{N}\right.$ and $\left.89^{\circ} 21^{\prime} \mathrm{E}\right)$ in Satkhira district, Bangladesh. The trees were fairly straight and free from natural defects. Two of them were taken from waterlogged and rest two were selected from non-waterlogged region.

After felling, each bole was cut into $1.5 \mathrm{~m}$ logs. Samples were collected from three different heights, i. e., the base, middle, and top. In each case, the specimens were collected from near the center of the log avoiding the pith, which ensured that specimens were made mostly from heartwood because heartwood is usually specified for commercial timber.

ASTM D 1037-100 (Anonymous, 2006) standard procedures were followed to determine the physical properties. Mechanical properties were accomplished by DIN 52362 (DIN 1984). Physical and mechanical properties were done for each portion of each type of the tree. The results are reported in average for each property to conclude the findings.

\footnotetext{
*Corresponding author: E-mail: atanu03ku@yahoo.com
} 
The data obtained during the laboratory test were analyzed for the depiction of physical and mechanical properties. Microsoft Office Excel 2013 and SPSS (Statistical Package of Social Survey) 11.5 software were used for the analysis of both type of properties.

\section{Results and discussions}

\section{Physical properties}

The moisture content in air dry condition of waterlogged tree was $23.5 \%$ and non-waterlogged tree was $18.0 \%$. The independent sample t-test shows a significant difference between two types of wood which was found in different environmental condition (Table 1). Water logged tree showed more moisture content (\%) compared to non-waterlogged tree. Waterlogged tree gets water throughout the year. So, its cell wall density is less to contain more water (Arnold and Mauseth, 1999).

It was found that air dry density of the wood of waterlogged tree was $870 \mathrm{~kg} / \mathrm{m}^{3}$ and non-waterlogged tree was $882 \mathrm{~kg} / \mathrm{m}^{3}$ (Fig. 1). The oven dry density was 780 and $850 \mathrm{~kg} / \mathrm{m}^{3}$ respectively for the wood of waterlogged and non-waterlogged tree (Fig. 1). The density of both types was more for non-water logged tree than that of waterlogged tree. The independent sample t-test showed that there is a significant difference between waterlogged and non-waterlogged tree for both types of density (Table 1). Cell wall density is less in the tree grown in waterlogged_area. This causes producing lower density wood in such areas (Arnold and Mauseth, 1999). Low cell wall density is well recognized to lead to low wood density (Haygreen and Bowyer, 1989; Desch and Dinwoodie, 1996).

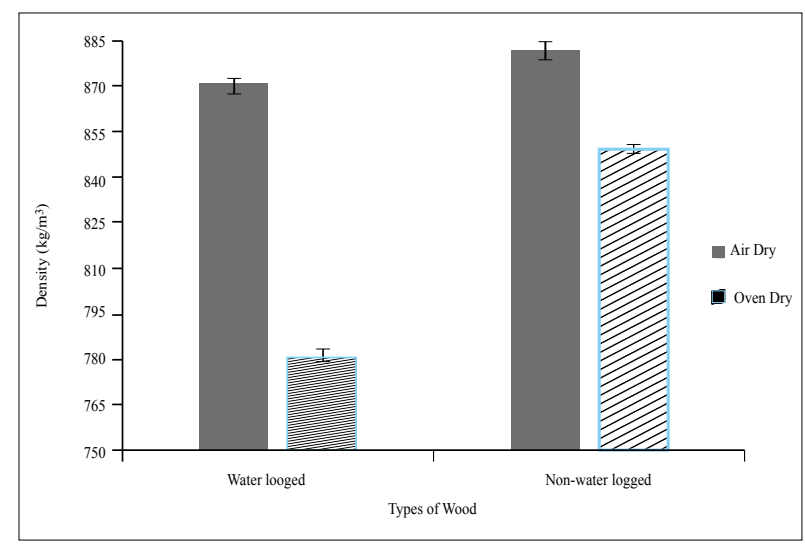

Fig. 1. Density of wood of waterlogged and on-waterlogged tree
In this study, tangential shrinkage (TS) was 3.29, radial shrinkage (RS) 2.54, longitudinal shrinkage (LS) 0.20 and volumetric shrinkage (VS) $6.05 \%$ for the wood of waterlogged tree. The respective values in these positions were $3.50,2.67,0.23$ and $6.20 \%$ for the wood of non-waterlogged tree (Fig. 2). The shrinkage of wood depends on density of wood. High density wood shows high shrinkage. In this study, wood of non-waterlogged tree showing higher density demonstrated higher shrinkage. Similar findings were observed in other studies (Koubaa and Smith, 1959; Karki, 2001; Pliura et al., 2005; Kord et al., 2010). Statistical analysis also proved significant_difference between the two types of wood for the shrinkage values at the four positions (Table 1).

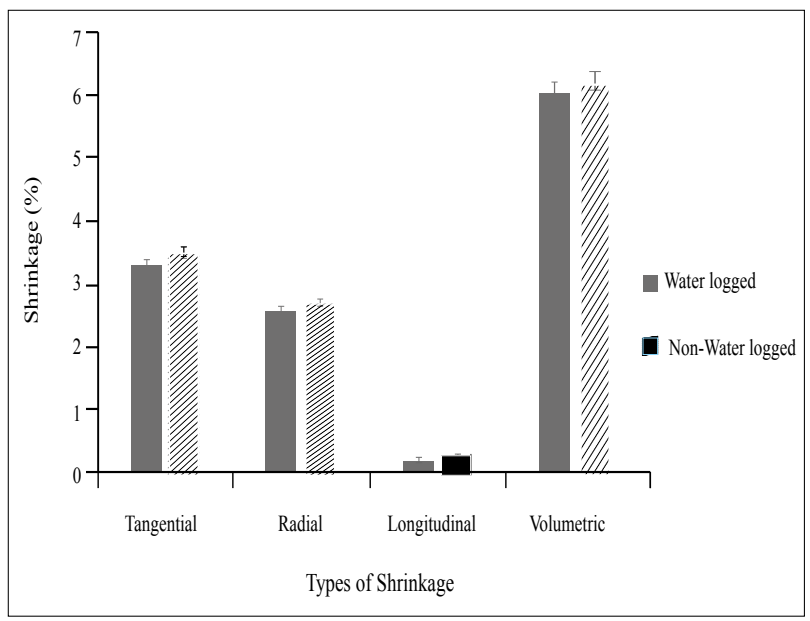

Fig. 2. Shrinkage of wood of waterlogged and non-waterlogged tree

Fig. 3 illustrates that swelling at tangential position (TSW) was 2.73, radial position (RSW) 1.87, longitudinal position (LSW) 0.42 and volumetric position (VSW) 4.84\% for the wood of non-waterlogged tree. The wood of waterlogged tree showed that swelling was 2.59, 1.67, 0.35 and $4.45 \%$ respectively at tangential, radial, longitudinal and volumetric positions. The swelling at the four positions of waterlogged wood was significantly different from the wood of non-waterlogged tree (Table 1). Density is positively correlated with swelling which increases with increasing wood density (Koubaa and Smith 1959; Karki 2001; Pliura et al., 2005). The swelling of wood of non-waterlogged tree was higher than that of waterlogged wood as the wood density of non-water logged tree was more in comparison to the wood of waterlogged tree. 
Table I. Summary of independent sample t-test of physical properties

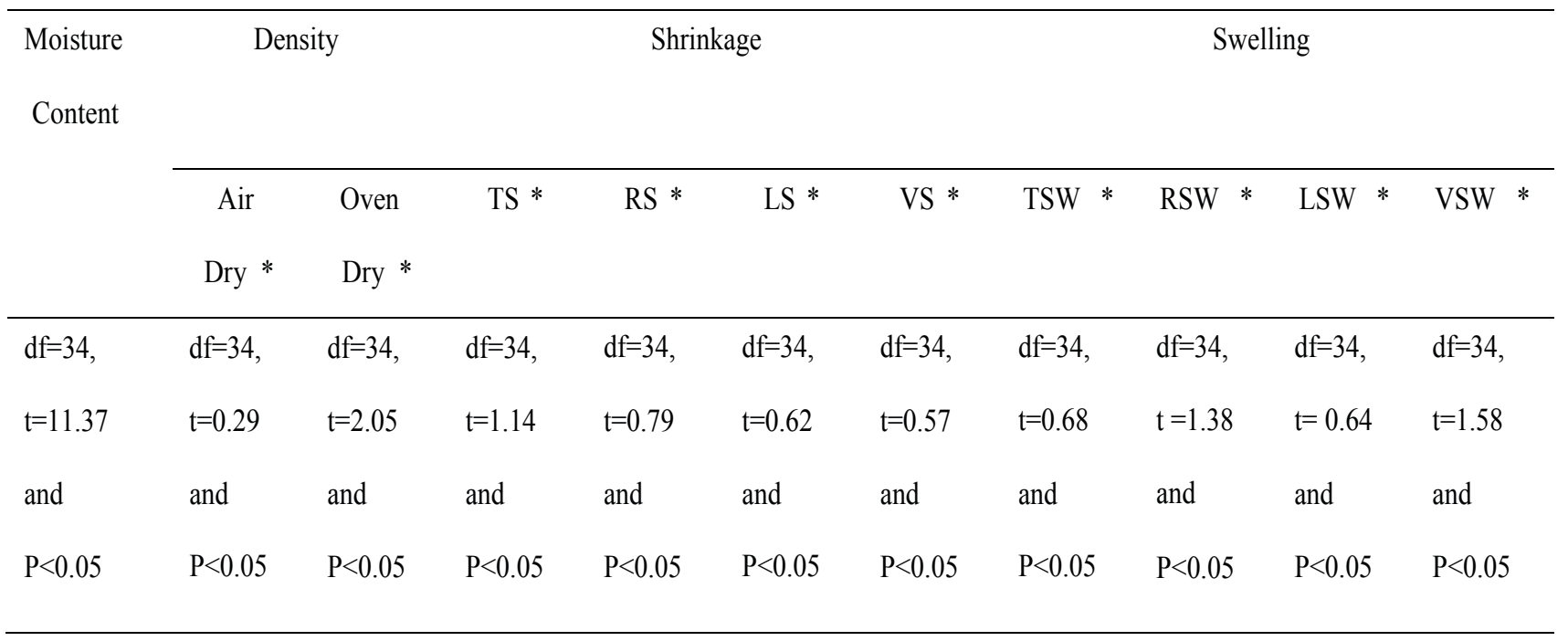

*= Significant at $\quad \mathrm{P}<0.05$

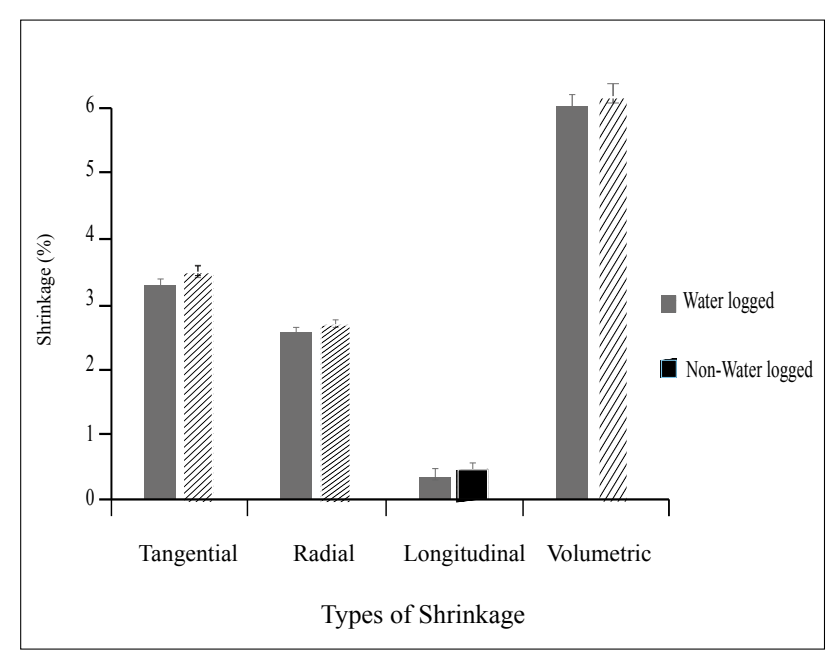

Fig. 3. Swelling of wood of waterlogged and non-waterlogged tree

\section{Mechanical properties}

The tensile strength of the wood of waterlogged tree was 73.9 $\mathrm{N} / \mathrm{mm}^{2}$. It was $78.7 \mathrm{~N} / \mathrm{mm}^{2}$ for the wood of non-water logged tree (Fig. 4). Tensile strength of non-waterlogged tree showed higher value. Tensile strength is enhanced with wood density. Wood density of non-waterlogged tree was higher. This finding was similar to the previous investigations (Haygreen and Bowyer 1989; Desch and Dinwoodie, 1996). Moisture content influenced the tensile strength of the wood of waterlogged tree. Increasing moisture content decreases the tensile strength. This relationship was observed by Gerhards (Gerhards 1982) and Matan and Co-workers (Matan and Kyokong 2003). Significant difference was found between the tensile strength of two types of wood by independent sample t-test (Table 2).

Fig. 5. shows that the Modulus of Rupture (MOR) was $117 \mathrm{~N} / \mathrm{mm}^{2}$ for the wood of waterlogged tree but it was $127 \mathrm{~N} / \mathrm{mm}^{2}$ for the wood of non-waterlogged tree. The MOR was higher for the wood of non-waterlogged tree. Statistical analysis showed significant difference between the wood of waterlogged and non-waterlogged tree (Table 2 ). Density and moisture content influence the MOR of wood. Haygreen and Co-workers (Haygreen and Bowyer, 1989) and Desch and Dinwoodie (1996) found that the MOR increased with the increase of density of wood. Gerhards (Gerhards, 1982) and Matan and Kyokong (2003) stated that decrease of moisture content enhances the MOR of wood. This study was similar with previous study. Wood of non-waterlogged tree had higher density and lower moisture content than the wood of waterlogged tree. 


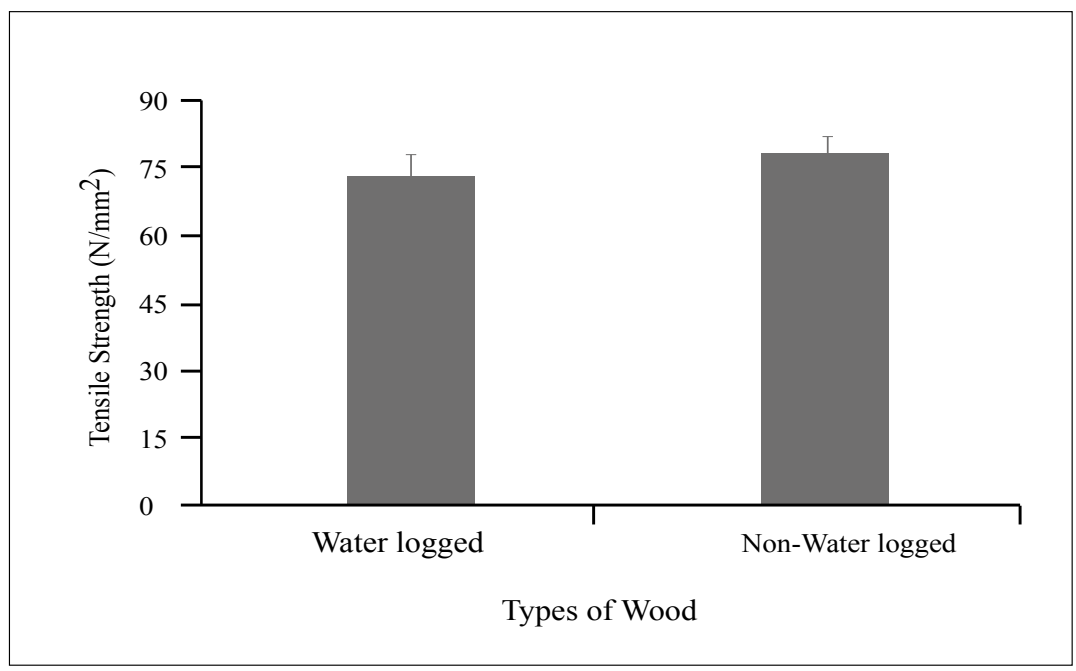

Fig. 4. Tensile strength of wood of waterlogged and non-waterlogged tree

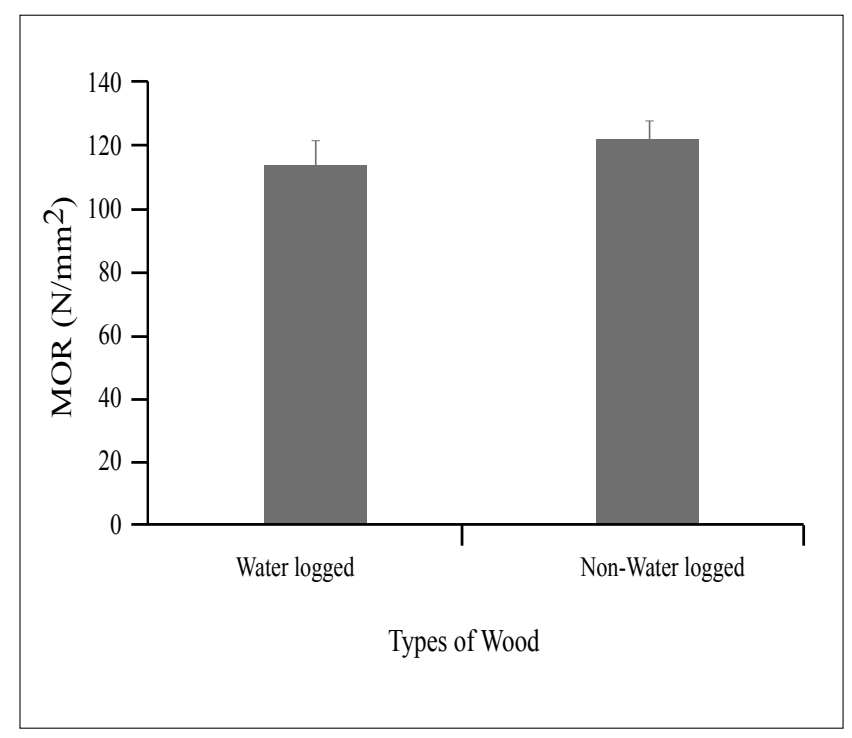

Fig. 5. Modulus of Rupture (MOR) of wood of waterlogged and non-waterlogged tree

The wood of waterlogged tree produced the Modulus of Elasticity (MOE) $1880 \mathrm{~N} / \mathrm{mm}^{2}$ (Fig. 6). The MOE was 1950 $\mathrm{N} / \mathrm{mm}^{2}$ for the wood of non-waterlogged tree (Fig. 6). The MOE was more for non-waterlogged tree due to higher density and low moisture content. In the previous studies, similar effect of density on MOE was observed (Haygreen and Bowyer, 1989; Desch and Dinwoodie, 1996). The related outcome of moisture content was perceived by Gerhards (Gerhards, 1982) and Matan and Kyokong (2003). Significant difference for MOE between the wood of waterlogged tree and non-waterlogged tree was ascertained by independent sample t-test (Table 2).

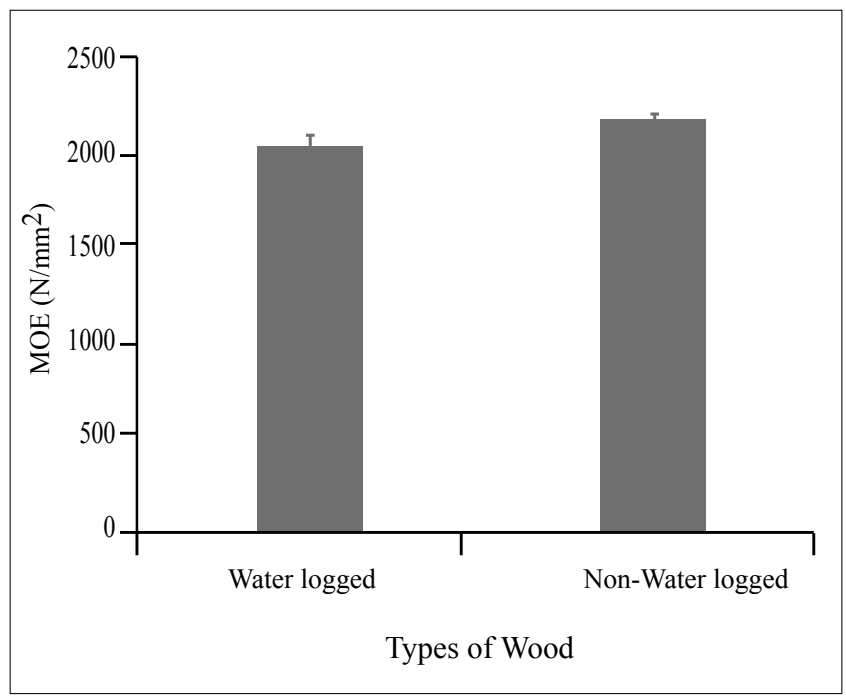

Fig. 6. Modulus of Elasticity (MOE) of wood of waterlogged and non-waterlogged tree 
Table II. Summaries of independent sample t-test of mechanical properties

\begin{tabular}{ccc}
\hline Tensile Strength* & MOR* & MOE $*$ \\
\hline$d f=34, \mathrm{t}=0.86$ and $\mathrm{P}<0.05$ & $\mathrm{df}=34, \mathrm{t}=5.03$ and $\mathrm{P}<0.05$ & $\mathrm{df}=34, \mathrm{t}=0.37$ and $\mathrm{P}<0.05$ \\
\hline$*$ = Significant at $\mathrm{P}<0.05$ &
\end{tabular}

\section{Conclusion}

The wood of $A$. nilotica has a great value for making different types of agricultural instruments and vehicle parts. The properties of the wood vary according to environmental and genetic factors. Knowledge of the properties helps to use the wood properly. This study showed that the mechanical and physical wood properties of $A$. nilotica grown in waterlogging condition were slightly lower than those of non-waterlogging condition. Further study is required to find out the variation of minute structures of wood of $A$. nilotica grown in different environment.

\section{References}

Arnold DH and Mauseth JD (1999). Effects of Environmental Factors on Development of Wood. American Journal of Botany 86(3): 367-371

Anonymous, ASTM (AMERICAN SOCIETY FOR TESTIG MATERIALS) (2006). ASTM D 1037-100. Standard Test Methods for Evaluating Properties in of wood-based fiber and particle panel materials. ASTM International, West Conshohocken

Anonymous, DIN (DEUTSCHES INSTITUT FUR NORMUNG) (1984). DIN 52362. Testing of Wood Chipboards Bending Test, Determination of Bending Strength. Normen Fur Holz Faserplaten Spanplatten Sperrholz, Berlin.

Barnett JR and Jeronimidis G (2003). Wood Quality and Its Biological Basis. CRC Press LLC, 2000 Corporate Blvd., N.W., Boca Raton FL 33431, USA ISBN 0-8493-2819-5. pp. 1-226.
Desch HE and Dinwoodie JM (1996). Timber Structure, Properties, Conversion and Use. $7^{\text {th }}$ Ed.(Macmillan press Limited. London), p. 306.

Gerhards CC (1982). Effect of Moisture Content and Temperature on The Mechanical Properties of Wood: An Analysis Of Immediate Effects Wood and Fiber, 14(1): 4-36.

Hamad A, Mefarrej A and Elkhalifa KF (2006). One-year Field Performance of Some Acacia and Prosopis species in Saudi Arabia. Asian J. Plant Sci. 5(5): 763-766.

Haygreen JG and Bowyer JL (1989). Forest Products and Wood Science, Iowa State University Press, USA.

Karki T (2001). Variation of wood density and shrinkage in European aspen (Populus tremula). Holz J 59: 79-84.

Kord B., Kialashaki A and Kord B (2010). The within-tree variation in wood density and shrinkage, and their relationship in Populus euramericana. Turk J Agric For 34: 121-126.

Koubaa RW and Smith JH G (1959). The effect of some genetic and environmental factors on wood quality in poplar. Pulp \& Paper J 59: 37-38.

Matan N and Kyokong B (2003). Effect of moisture content on some physical and mechanical properties of juvenile rubberwood (Hevea brasiliensis Muell. Arg.). Songklanakarin J. Sci. Technol. 25(3): 327-340. 
Pliura A, Yu Q, Zhang SY, Mackay J, Pierre P and Bousquet $\mathrm{J}$ (2005). Variation in wood density and shrinkage and their relationship to growth young poplar hybrids crosses. Forest Sci J. 51: 472-482.

Punches J (2004). Tree Growth, Forest Management, and Their Implications for Wood Quality. PNW 576, 8 pages, illustrated.
Van Wyk B, Van Wyk, P and Van Wyk BE (2000). Photographic guide to trees of southern Africa. Briza Publications, Pretoria.

Received: 22 March 2015; Revised: 26 April 2015; Accepted: 30 June 2015. 